\title{
Sick leave due to back pain in a cohort of
}

\section{young workers}

A Van Nieuwenhuyse ${ }^{(\mathrm{a}, \mathrm{b})}$, A Burdorf $^{(\mathrm{c})}, \mathrm{G}$ Crombez $^{(\mathrm{d})}, \mathrm{G}$ Verbeke $^{(\mathrm{e})}, \mathrm{R}$ Masschelein $^{(\mathrm{b})}$, Ph Mairiaux ${ }^{(\mathrm{f})}$, GF Moens ${ }^{(\mathrm{b}, \mathrm{g})}$, and the BelCoBack Study Group

(a) Department of Public Health and Surveillance, Scientific Institute of Public Health, Brussels, Belgium

Juliette Wytsmanstraat 14, 1050 Brussels, Belgium

Phone: +32 26425750

Fax: +32 26425410

Email: an.vannieuwenhuyse@wiv-isp.be

(b) Department of Public Health, Section of Occupational, Environmental and Insurance Medicine, Katholieke Universiteit Leuven

Kapucijnenvoer 35/5, 3000 Leuven, Belgium

Phone: +3216337085

Fax: +32 16336997

(c) Department of Public Health, Erasmus MC, University Medical Center Rotterdam, Rotterdam, The Netherlands

(d) Department of Psychology, University of Ghent, Ghent, Belgium

(e)Department of Public Health, Biostatistical Centre, Katholieke Universiteit Leuven, Leuven, Belgium

(f) Occupational Health and Health Education Unit, Department of Public Health, University of Liège, Liège, Belgium

(g) External Service for Prevention and Protection at Work IDEWE, Leuven, Belgium 


\section{ABSTRACT}

Purpose: Evidence on risk factors for sick leave from prospective studies in work settings is limited. Furthermore, most available studies focused on workers with substantial low back disorders. These studies consistently report that physical work factors constitute a hindrance to work. However, it remains unclear whether the same risk factors are relevant in workers with less severe conditions or in early phases of the development of back pain. Therefore, this article aims to study risk factors for the occurrence of sick leave due to low back pain (LBP) among young workers with no or a modest history of back pain.

Methods: Participants were 716 young healthcare or distribution workers with no or minimal antecedents of LBP in the year before inclusion. We investigated the role of potential physical, psychosocial and individual risk factors at baseline on the occurrence of sick leave due to LBP one year later. To this purpose, we used Cox regression with a constant risk period.

Results: Six percent (95\%CI: 4.1-7.6) of the workers reported sick leave one year later; they accounted for $12 \%$ of the sick leave days independent of cause. A non-stimulating psychosocial work environment turned out to be the strongest risk factor for sick leave due to LBP (RR 6.08; 95\%CI: 1.42 - 26.07). Physical factors were not predictive.

Conclusions: In the early phases of back pain and in less severe conditions, the main benefit of interventions lies in targeting the organisation and design of jobs to create a challenging professional environment.

\section{Key words}

low back pain, sick leave, psychosocial work environment, prospective, young workers 


\section{INTRODUCTION}

Back pain is a major health and economic problem in Western industrialized societies. It is a primary reason for health care use and work inability, and leads to substantial costs for society and industry. Cost-of-illness studies of back pain in the Netherlands, Sweden and the U.K. have concluded that the main burden imposed by back pain is related to production loss attributable to work absenteeism. These costs supersede the health care costs [Ekman et al. 2005; Van Tulder et al. 1995; Maniadakis and Gray 2000].

In contrast to knowledge about risk factors for low back pain (LBP), knowledge about risk factors for sick leave from back disorders remains unsatisfactory [Alexanderson and Norlund 2004]. First, the number of prospective studies is limited and the resulting evidence on the role of physical, psychosocial and individual factors is unclear. Many researchers assumed that a focus upon risk factors for the development of LBP would automatically prevent subsequent sick leave. Recent evidence has shown that this assumption may not be valid. It seems that different sets of factors may have to be addressed in the prevention of LBP and in the prevention of sick leave [Ijzelenberg et al. 2004; Gheldof et al. 2005; Ijzelenberg and Burdorf 2005]. Therefore there has been a call for longitudinal studies focusing on sick leave [SBU 2004]. Second, almost all studies have focused on study populations with a considerable proportion of workers with a history of LBP. The magnitude of and the risk factors for back-related sick leave in individuals with no or limited antecedents of LBP are largely unknown.

Some evidence exists on factors that predict the duration of sick leave in workers in the beginning of a LBP-related sick leave episode, i.e. radiating pain, high levels of disability and social dysfunction, social isolation, being an older female, and receiving a high level of compensation. With regard to work-related factors, patients with low back pain at the highest risk for long term absence are workers doing heavy physical work. For the psychosocial factors, however, the evidence remains inconclusive. In spite of well known effects of history of low back pain on recurrences of back pain, history of LBP does not influence the duration of sick leave due to LBP [Steenstra et al 2005]. History of LBP was reported as prognostic for a more frequent drop 
out from work by Wasiak and co-workers [Wasiak et al. 2004]. Similarly, musculoskeletal pain and combinations of pain predicted sickness absence spells among municipal workers during a three-year follow-up study [Kääriä et al 2012]. Apart from the effect of previous pain, the evidence of the respective roles of physical, psychosocial and individual risk factors on the frequency of sick leave remains inconclusive.

In Belgium, the compulsory social health insurance covers the entire population and is organised by sickness funds. When an employee starts sickness absence, he/she send a medical certificate of the treating physician to the employer who pays the first 2-4 weeks of work incapacity. If work incapacity continues, the patient applies for a social security benefit by sending another medical certificate to the medical adviser of the sickness fund. Claim assessment, followup evaluation and the decision about benefit entitlement are done by the medical adviser. There is no time limit for coverage [Du Bois et al. 2008].

Furthermore, every employer is obliged by law to organize occupational health care for the employee. Most employers hire the services of an external occupational health care service. A few large companies have an internal occupational health care service. The main role of the occupational physician is to prevent occupational diseases and accidents. The occupational physician is hardly involved in the sick leave process. It is only recently that employees on sick leave have been legally entitled to contact the occupational physician to discuss return to work options [Tiedtke D et al. 2012].

In a sample of young workers with no or a modest history of back pain, we aimed

(1) To describe the occurrence, the duration, and the frequency of sick leave due to LBP,

(2) To investigate the effect of work-related and individual factors on the occurrence of sick leave due to LBP, and

(3) To assess the impact of each identified risk factor on the occurrence of sick leave among the workers exposed to one of these factors and among the entire study population. 


\section{MATERIALS AND METHODS}

\section{Subjects and methods}

The BelCoBack Study (Belgian Cohort Study on Low Back Pain) is a prospective study. Methods have been described in detail before [Van Nieuwenhuyse et al. 2006]. In summary, in 2000 and 2001 participants were recruited among the employees of four healthcare institutions and two distribution companies throughout Belgium and baseline measurements were obtained. Employment in either sector is associated with elevated risks for LBP. However, the choice of these two sectors (and not for example the construction sector) was practical: the collaboration partner IDEWE, as an important occupational health service, recruited the participants among the employees of their clients, many of which are active in the health care and distribution sectors. The recruitment took place as a result of the annual medical examination by the occupational health physician. In Belgium, such an examination is obliged by law for workers exposed to occupational risks [Royal Decree May $28^{\text {th }} 2003$ ]. To minimise dropout, only workers with a tenured position or equivalent were included. Furthermore, to reduce the influence of age and of prior episodes of LBP, participants had to be no older than 30 years at the time of intake and had to have been free of episodes of LBP of seven or more consecutive days during the twelve months before intake in the study. Of 1672 eligible employees, 1200 (72\%) agreed to participate. However, during a first contact, 159 were excluded because they did not meet the last inclusion criterion, leaving a sample of 1041 workers. Of those 1041 workers, 972 (93\%) completed the questionnaire at baseline.

One year later (2001-'02), participants were requested again to fill in a questionnaire. Of the 972 workers who responded at baseline, $800(82 \%)$ returned the questionnaire. Questionnaires at baseline and at follow-up were distributed within the companies by the research assistants. The majority of workers filled in the questionnaire at home and sent it back to the research assistants. In case of non-response, two reminders were sent.

For the longitudinal analyses described in this paper, a cohort was identified of 851 employees with a minimal experience of at least two months in their function at intake. An interval of at least two months was considered sufficient to appreciate the work constraints in a function. 
The questionnaire at one year of follow-up was available for 716 of these 851 workers (response of $84 \%$, loss to follow-up of $16 \%$ ).

The study protocol was approved by the local commission for medical ethics, and an informed consent was given by all included employees before their participation in the study.

\section{Data collection}

Questionnaires at baseline. At baseline, self-reported questionnaires were used to register factors that may be related to low back disorders, i.e. (i) physical load at work and during leisure time, (ii) psychosocial work characteristics and (iii) individual variables.

Questions on current physical workload [Somville and Mairiaux 2003] addressed (1) the duration of working in awkward postures, (2) the duration of exposure to whole body vibration, (3) the intensity and, where indicated, the frequency of manual materials handling such as lifting, carrying, pushing, or pulling of loads, (4) static work postures (that is, standing and sitting for long periods) and (5) ability to change posture regularly. Duration, frequency, and intensity were rated on three or four point ordinal scales. Furthermore, we addressed the seniority in the current function and the working schedule (percentage of employment, day or night duty). Additional questions on (at least weekly) sporting activities, engagement in construction and embellishment work at home, and on motor vehicle driving outside the work ( $\mathrm{km} / \mathrm{year})$ served to assess the physical load during leisure time.

Psychosocial work characteristics were evaluated with the 43-item Job Content Questionnaire [Karasek and Theorell 1990]. The different items were measured on four point Likert scales, ranging from "completely disagree" to "completely agree", yielding a sum score for each dimension. Based on the Demand-Control-Support model of Karasek and Theorell, the following dimensions were taken into account: skill discretion (six items), decision authority (three items), psychological job demands (five items), supervisor and co-worker support (four items each), job insecurity (five items), and job dissatisfaction (five items). For the analyses, the psychosocial work characteristics were categorised into tertiles. 
Individual variables included (1) age, sex, language, and educational level as demographic factors, (2) smoking behaviour, body mass index, perceived general health and complaints of the neck, back, upper or lower limbs in the year before inclusion as health related factors, and (3) pain related fear, catastrophising about pain, negative affectivity, and somatisation as psychological factors. The questionnaire on individual and health related factors was derived from the standardised Nordic Questionnaires for the analysis of musculoskeletal symptoms [Kuorinka et al. 1987]. For the assessment of psychological concepts, we used the Modified Tampa Scale of Kinesiophobia [Vlaeyen and Crombez 1998], the Pain Catastrophizing Scale [Sullivan et al. 1995], the Positive Affectivity Negative Affectivity Scales [Watson et al. 1988], and an adapted version (29 items) of the Psychosomatic Symptom Checklist [Van Dixhoorn and Duivenvoorden 1985], respectively. All items were scored on four or five point Likert scales and for each concept a total score was calculated. For the analyses, these scores were split up into tertiles. Body mass index (BMI) was categorized as BMI $<20$, BMI 20-<25 (normal), BMI 25-<30 (overweight), and BMI $\geq 30$ (obese). Language was collected since a previous study in Belgium has shown that back injuries with a longer sick leave were more prominent in the French-speaking part of the country compared to the Flemish speaking communities. As such, language may represent subtle cultural language-linked factors and/or regional differences in economic climate that play a role in the sick leaving process [Mazina D et al. 2012].

Questionnaires at one year of follow up. One year later, participants completed another questionnaire. At that moment, workers were asked, among others, if they had stayed at home because of low back complaints since the start of the study about 12 months ago (yes/no). The occurrence of sick leave due to LBP after one year of follow-up, i.e. the outcome for this article, was thus registered as the proportion of workers who stayed home because of LBP in the first year of follow-up. Sick leave was defined as any absence from work however short. If 'yes', participants were asked to further detail the number of sick leave spells ("how many times") and the total duration of sick leave ("how many days in total") [Kuorinka et al. 1987; Von Korff et al. 1992]. As described, all sick leaves from work in Belgium have to be medically certified and are then compensated. 


\section{Analytic methods}

Univariate analyses were performed by means of Chi-square or Fisher Exact tests (categorical variables) and Mann Whitney U or unpaired T-tests (continuous variables). For the multivariate analyses, we opted for a Cox-regression with a constant period of risk for all subjects in order to obtain relative risk estimates rather than odds ratios, which would result from logistic regression [Thompson et al. 1998]. Age and gender were included as confounders, irrespective of their relation with LBP. Variables that met the $10 \%$ level of significance in the univariate analyses were considered for inclusion in the multivariate analyses. We calculated correlation coefficients among these variables as an approximate manner to detect possible multicollinearity. In the final multivariate models, backward selection was used retaining variables with a $\mathrm{P}$ value less than 0.05 . Analyses were conducted with the SPSS package (version 18). In a last step, we calculated the attributable fraction among the exposed workers $\left(\mathrm{AF}_{\text {exposed }}\right)$ as well as the population attributable fraction among the entire study population $\left(\mathrm{PAF}_{\text {total }}\right)$ for those variables that were found to constitute risk factors. The $\mathrm{AF}_{\text {exposed }}$ estimates the fraction of exposed cases that would not have occurred if exposure had not occurred. The $\mathrm{PAF}_{\text {total }}$ estimates the fraction of all cases that would not have occurred if exposure had not occurred [Rothman and Greenland 1998]. 


\section{RESULTS}

\section{Descriptive statistics}

\section{Risk factors}

The study characteristics for the 716 participants are given in Table 1. The Table is structured as follows: (i) physical load at work and during leisure time, (ii) psychosocial work characteristics and (iii) individual variables. This last group of variables includes demographic, health-related and psychological factors. Psychosocial work characteristics and psychological factors have been categorized into tertiles. Categorical variables are given in Table 1a and continuous variables in Table $1 \mathrm{~b}$.

Out of the 716 workers, $64 \%$ were employed in the health care sector and $36 \%$ in the distribution sector and $61 \%$ were women. We registered a median age of 26 years (interquartile range of 5 years) and a median seniority in the current function of 3 years (interquartile range of 4 years). $88 \%$ had a full time employment.

The majority of the participants reported either higher education of non-university level (37\%) or higher secondary/professional education (40\%). Although we had tried to limit previous antecedents of back pain by including only workers free of episodes of LBP lasting seven consecutive days or more in the year before inclusion, $48 \%$ of the participants reported pain of the lower or upper back in the 12 months before inclusion. More specifically, $10 \%$ reported some pain in the upper back and 43\% reported some LBP (but not lasting seven consecutive days or more) in the 12 months before inclusion. 38 workers (5\%) interrupted their normal activities at home, outside the home or at work because of LBP in the year before inclusion; the median number of days of these interruptions was 4.5 days with an interquartile range between 2 and 7 days. In this young population aged 30 years or younger, 47\% rated their health as 'very good'; the remaining $53 \%$ gave a rating of 'moderate to fair'. 


\section{Study outcome}

After one year of follow-up, $42(6 \%, 95 \% \mathrm{CI}$ : 4 - 8) of the 716 workers reported sick leave from work due to LBP. There was no significant difference between men and women (Table 2). Although only 42 workers reported back-related sick leave, sick leave due to LBP was substantial with a median duration of 10 days (interquartile range between 5 and 21 days). Notably, 35 (84\%) of the 42 workers took sick leave as a single episode. Collectively, LBP-related sick leave accounted for 696 days or $12 \%$ of all the sick leave days in the population of 716 workers.

\section{Risk factors for the occurrence of sick leave due to LBP}

\section{Univariate analyses}

Results of univariate analyses are presented in Table $3 \mathrm{a}$ (categorical variables) and $3 \mathrm{~b}$ (continuous variables). With regard to the physical load, two factors were significantly related to back-related sick leave in the following year, i.e. motor vehicle driving outside work (MannWhitney $\mathrm{U}$ test, $\mathrm{P}=0.018$ ) and driving vehicles or machines at work. For the latter, a moderately elevated risk was observed for driving up to six hours a day (RR 2.54, 95\%CI 1.27-5.08), but there was no evidence for a clear dose-response relationship. None of the variables concerning awkward working postures, manual materials handling, or static work postures were predictive. As to the psychosocial work load, one dimension of the Karasek model turned out to be predictive for sick leave in the following year, i.e. a lack of 'possibilities to develop skills'. Three- to four-fold elevated risks were observed for workers who reported low (RR 3.86, 95\%CI 1.36-10.99) or moderate (RR 3.06, 95\% CI 1.01-9.35) 'possibilities to develop skills' at work in comparison to their colleagues who indicated high possibilities at baseline. Three individual factors were related to the occurrence of sick leave in the following year: (1) general health perceived as moderate to fair (RR 2.82, 95\%CI 1.40-5.56), (2) obesity defined as a BMI of 30 or higher (RR 2.94, 95\% CI 1.29-6.67) and (3) complaints of the upper limbs in the year before inclusion (RR 2.20,95\%CI 
1.19-4.07). None of the psychological variables predicted sick leave (neither as categorical nor as continuous variables).

\section{Multivariate analyses}

The following variables, associated with a $\mathrm{P}$ value of $\leq 0.10$ in univariate analyses, were considered for inclusion in multivariate analyses: the physical factors (a1) motor vehicle driving outside the work (Mann Whitney U test, $\mathrm{P}=0.018$ ), (a2) driving vehicles or machines at work (Chisquare test, $\mathrm{P}=0.024$ ), and (a3) inability to change posture regularly (Chi-square test, $\mathrm{P}=0.076$ ); the psychosocial work characteristic (b1) possibilities to develop skills (Chi-square test, $\mathrm{P}=0.023$ ); and the individual variables (c1) perceived general health (Chi-square test, $\mathrm{P}=0.002)$, (c2) complaints of the upper limbs in the year before inclusion (Chi-square test, $\mathrm{P}=0.011$ ), (c3) body mass index (Chi-square test, $\mathrm{P}=0.021$ ), and ( $\mathrm{c} 4)$ education (Chi-square test, $\mathrm{P}=0.061$ ). Age and gender were included as epidemiological confounders, although they were not significantly related to backrelated sick leave (Mann Whitney $\mathrm{U}$ test, $\mathrm{P}=0.307$ and Chi-square test, $\mathrm{P}=0.153$, respectively).

Multivariate analyses were based on backward selection. We constructed a model for each comprehensive combination of unrelated variables significant at $\mathrm{P} \leq 0.10$ in univariate analyses. In Table 4, we show the results of a model with unrelated variables. In case of interrelationships, the most significant variable was included in this model. This model showed a strong and significant relationship between a lack of 'possibilities to develop skills' at work and subsequent sick leave for LBP in the following year. In contrast with colleagues who reported high 'possibilities to develop skills' at baseline, workers with moderate and especially low 'possibilities to develop skills' showed a five- (RR 5.01, 95\%CI: 1.10-22.88), respectively six-(RR 6.08, 95\%CI: $1.42-26.07)$ times higher risk on sick leave due LBP one year later. Furthermore, the risk ratio for obese workers as opposed to workers with a normal BMI was 3.41 (95\%CI: $1.37-8.48$ ). 


\section{Attributable fractions}

Table 4 presents the proportion of LBP-related sick leave that can be attributed to the risk factors identified among exposed workers $\left[\mathrm{AF}_{\text {exposed }}\right]$ and among the entire study population $\left[\mathrm{PAF}_{\text {total }}\right]$. From these data, it follows that a lack of 'possibilities to develop skills' is responsible for a proportion of LBP-related sick leave comparable to that of 'obesity', which constitutes a factor that cannot be changed by workplace interventions. 


\section{DISCUSSION}

\section{Principal findings of the study}

This study aimed at investigating the development of sick leave due to LBP in a population of young workers with no or a modest history of back complaints. We have shown that only a small proportion of workers listed sick because of LBP and that the decision to report sick was influenced to a great extent by a poor psychosocial work environment. Once workers were at home, they failed to return to work for quite a long time.

More specifically, it was low 'possibilities to develop skills' that turned out to be the most important occupational risk factor for back-related sick leave. This finding may suggest that back-related sick leave is mainly taken by workers who lack professional challenges. The perceived lack of professional challenges may have led to a lower threshold to take sick leave.

Moreover, low 'possibilities to develop skills' was responsible for a proportion of LBPrelated sick leave comparable to that of 'obesity', which constitute a factor that cannot be changed by workplace interventions. Thus, the influence of the environment is important and exists in job organization and design to create a challenging professional environment.

\section{Strengths and weaknesses}

The main strength of the BelCoBack Study is its prospective design, respecting the temporal relationship between cause and consequence. Furthermore, the study took a different scope by focusing on young workers with no or a modest history of back pain. This choice allowed studying more accurately the development of back pain [Van Nieuwenhuyse et al. 2006; Van Nieuwenhuyse et al. 2004] and sick leave. With respect to the multi-factorial nature of LBP, several categories of variables were included: physical, psychosocial and individual.

Sick leave was registered by self-reported questionnaires because systematic company records on (cause-specific) absenteeism are not available to the occupational health physician in 
Belgium. The majority of studies have found acceptable validity for self-reports [Stapelfeldt et al 2012]. However, a Dutch study in blue collar workers reported low sensitivity of self-reports (55\%) to detect frequency of spells [Van Poppel et al. 2002]. In our study, the taking of sick leave (yes/no), and, if 'yes, the number of spells and the number of sickness absence days, were questioned one year after the intake. The reason was practical: examinations in the BelCoBack Study were organized in relation with the annual medical examination by the occupational health physician to limit the extra load of the study for the companies. No diary methods in between were used. The recall period of one year is long and may have led to some underreporting. More specifically, for duration of sickness absence, there is evidence that shorter recall periods could increase the precision of self-reporting with an optimum recall period of no longer than 2-3 months [Severens et al. 2000].

Furthermore, both the potential predictors and the outcome were reported by the workers themselves. Therefore, we cannot exclude common-source bias, i.e. bias due to collection from information from only one source that may lead to correlated reports of predictors and effects and thus false positive results [Dionne $\mathrm{S}$ et al. 2002]. It may be advisable in future studies to evaluate whether the self-reported lack of possibilities to develop skills, as important determinant, can be validated by assessments from supervisors or human resources personnel.

Due to the composition of the study population and the short follow-up, only 42 workers took sick leave because of LBP. As the number of sick days in these workers was substantial, it would have been interesting to analyse risk factors for the duration of sick leave. However, this was not possible due to lack of power.

\section{Comparison with the literature}

Only a limited number of studies have investigated physical and psychosocial characteristics as risk factors for the occurrence of sick leave due to LBP in a prospective way [Smedley et al. 1997; Hemingway et al. 1997; Wickstrom and Pentti 1998; Hoogendoorn et al. 2002; Tubach et al. 2002; Elders et al. 2003; van den Heuvel et al. 2004; Ijzelenberg et al. 2005; Bergstrom et al. 2007; Alexopoulos et al. 2008]. 
Our results are in line with those of two studies that have also focused on workers with limited back antecedents. In a Swedish follow-up study, Bergstrom and co-workers [Bergstrom et al. 2007] showed only one occupational factor to be predictive for sick-listing due to back or neck pain at the 18-month follow-up, i.e. 'few positive challenges at work'. One third of the initial cohort reported no back or neck pain in the year previous to baseline. Workers who indicated that the work was not meaningful or challenging and that their skills and knowledge were not useful at work had twice as high sick-listing as workers with the highest positive challenges (15\% vs. $7 \%$ ). Similarly, in a cohort study among British nurses, Smedley and colleagues [Smedley et al. 1997] found psychosocial factors, i.e. 'low mood', and not physical factors, to be predictive for sick leave due to LBP during follow-up. Lack of control, which reflects both skill discretion and decision authority, was also related to sick leave in a British follow-up study of office workers [Hemingway et al. 1997]. However, it has to be noted that the physical workload in office workers is negligible and therefore quite different from that of our population. Other studies have shown the important role of a good psychosocial working environment also for sick leaves in general [Duijts et al. 2007], which may suggest that it is not specific for workers with LBP.

The majority of cohort studies have included workers regardless of LBP history. In populations with LBP complaints, both physical and psychosocial workloads play a primary role in back-related sick leave. On the whole, the influence of the physical work environment seems more important than that of the psychosocial work environment, and in extreme occupations, i.e. populations with high disability rates at baseline and enormous physical loads $(15000 \mathrm{~kg} / \mathrm{day}) \mathrm{such}$ as scaffolders [Elders et al. 2003], the effect of physical load has been shown to dominate all other effects. The most likely explanation is that, in workers with a history of back pain, the high physical workload constitutes a hindrance to continue work.

In our population of young workers with no or limited antecedents of back pain, it was a poor psychosocial work environment that showed to be associated with future sick leave due to back pain, and may thus have led to a lower threshold to take sick leave. 


\section{Conclusion to health professionals and policy makers}

Physical work factors have been recognised for a long time as risk factors for LBP itself. Although literature about work-related risk factors for back-related sick leave is scarce, it is intuitively accepted that the same factors are also important for back-related sick leave. We reveal a more nuanced reality. In populations with LBP complaints, physical workload indeed plays a primary role in back-related sick leave. However, in workers with no or only limited LBP complaints at baseline, the physical workload does not appear to be the predominant reason for taking sick leave. Nevertheless, sick leave was substantial in this population and turned out to be associated mainly with a non-stimulating psychosocial work environment. Because the psychosocial work environment can be modified, this finding represents a potentially reversible cause of sick leave. 


\section{ACKNOWLEDGEMENTS}

The BelCoBack study was supported by the Belgian Federal Office for Scientific, Technical and Cultural Affairs (OSTC), projects PS/93/25, PS/12/26, PS/01/27.

The authors thank the other co-workers from the BelCoBack study group for their contribution to data collection and data processing: D. Pirenne, E. Persijn, A. Leys, and L. Moors.

\section{COMPETING INTEREST STATEMENT}

The authors declare that they have no conflict of interest.

\section{ETHICS APPROVAL}

The study protocol was approved by the Commission for Medical Ethics appointed by the College of Physicians $\mathrm{n}^{\circ} 117$ at the External Service for Prevention and Protection at Work IDEWE, Leuven, Belgium. A written, informed consent was given by all included employees prior to their participation in the study. 


\section{REFERENCES}

Alexanderson K, Norlund A (2004) Swedish Council on Technology Assessment in Health Care (SBU). Chapter 12. Future need for research. Scand J Public Health Suppl 63: 256-8.

Alexopoulos EC, Konstantinou EC, Bakoyannis G, Tanagra D, Burdorf A (2008). Risk factors for sickness absence due to low back pain and prognostic factors for return to work in a cohort of shipyard workers. Eur Spine J 17; 1185-92. Epub 2008 Jul 23.

Bergstrom G, Bodin L, Bertilsson H, Jensen IB (2007) Risk factors for new episodes of sick leave due to neck or back pain in a working population. A prospective study with an 18-month and a three-year follow-up. Occup Environ Med 64: 279-87.

Dionne SD, Yammarino FJ, Atwater LE, James LR. Neutralizing substitutes for leadership theory : leaderschip effects and common-source bias. J Appl Psychol 2002; 87: 454-64.

Du Bois M, Donceel P (2008). A screening questionnaire to predict no return to work within 3 months for low back pain claimants. Eur Spine J 17: 380-5.

Duijts SF, Kant I, Swaen GM, van den Brandt PA, Zeegers MP (2007). A meta-analysis of observational studies identifies predictors of sickness absence. J Clin Epidemiol 60:1105-15.

Ekman M, Johnell O, Lidgren L (2005) The economic cost of low back pain in Sweden in 2001. Acta Orthop 76: 275-84.

Elders LA, Heinrich J, Burdorf A (2003) Risk factors for sickness absence because of low back pain among scaffolders: a 3-year follow-up study. Spine 28: 1340-6.

Gheldof EL, Vinck J, Vlaeyen JW, Hidding A, Crombez G (2005). The differential role of pain, work characteristics and pain-related fear in explaining back pain and sick leave in occupational settings. Pain 113: 71-81.

Hemingway H, Shipley MJ, Stansfeld S, Marmot M (1997) Sickness absence from back pain, psychosocial work characteristics and employment grade among office workers. Scand J Work Environ Health 23: 121-9.

Hoogendoorn WE, Bongers PM, de Vet HC, Ariens GA, van Mechelen W, Bouter LM (2002) High physical work load and low job satisfaction increase the risk of sickness absence due to low back pain: results of a prospective cohort study. Occup Environ Med 59: 323-8. 
Ijzelenberg W, Molenaar D, Burdorf A (2004) Different risk factors for musculoskeletal complaints and musculoskeletal sickness absence. Scand J Work Environ Health 30: 56-63.

Ijzelenberg W, Burdorf A (2005) Risk factors for musculoskeletal symptoms and ensuing health care use and sick leave. Spine 30: 1550-6.

Kääria S, Laaksonen M, Leino-Arjas P, Saastamoinen P, Lahelma E (2012). Low back pain and neck pain as predictors of sickness absence among municipal employees. Scand J Public Health 40: 150-6.

Karasek R, Theorell T (1990) Healthy work. Stress, productivity and the reconstruction of working life, Basic book Inc, New York.

Kuorinka I, Jonsson B, Kilbom A, Vinterberg H, Biering-Sorensen F, Andersson G, Jorgensen K (1987) Standardised Nordic Questionnaires for the analysis of musculoskeletal symptoms. Appl Ergon 18: 233-7.

Maniadakis N, Gray A (2000). The economic burden of back pain in the UK. Pain 84: 95-103.

Mazina D, Donneau AF, Mairiaux P (2012). Determinants of sickness absence duration after an occupational back injury in the Belgian population. Am J Ind Med 55: 270-80.

Rothman KJ, Greenland S (1998) Modern epidemiology (2nd edition), Lippincott Williams \& Wilkins, Philadelphia: 295.

Royal Decree May $28^{\text {th }} 2003$ concerning the medical surveillance of employees. Belgian Law Gazette June $16^{\text {th }}$ 2003. http://www.meta.fgov.be

Severens JL, Mulder J, Laheij RJ, Verbeek AL. Precision and accuracy in measuring absence from work as a basis for calculating productivity costs in The Netherlands. Soc Sci Med. 2000 Jul;51(2):243-9.

SBU (2004) SBU summary and conclusions. Scand J Public Health 32 (suppl 63): 6-11.

Smedley J, Egger P, Cooper C, Coggon D (1997) Prospective cohort study of predictors of incident low back pain in nurses. BMJ 314, 1225-8.

Somville PR, Mairiaux Ph (2003) Evaluation des risques biomécaniques pour la colonne lombaire au moyen d'un questionnaire. Médecine du Travail et Ergonomie XL(1): 5-17.

Stapelfeldt CM, Jensen C, Andersen NT, Fleten N, Nielsen CV. Validation of sick leave measures: self-reported sick leave and sickness benefit data from a Danish national register compared to multiple workplace-registered sick leave spells in a Danish municipality. BMC Public Health. 2012 Aug 15;12(1):661. [Epub ahead of print]. 
Steenstra IA, Verbeek JH, Heymans MW, Bongers PM (2005). Prognostic factors for duration of sick leave in patients sick listed with acute low back pain: a systematic review of the literature. Occup Environ Med 62: 851-60.

Sullivan MJ, Bishop SR, Pivik J (1995) The pain catastrophising scale: development and validation. Psychol Assess 7: 524-32.

Thompson ML, Myers JE, Kriebel D (1998) Prevalence odds ratio or prevalence ratio in the analysis of cross sectional data: what is to be done? Occup Environ Med 55: 272-7.

Tiedtke C, Donceel P, Knops L, Désiron H, Dierckx de Casterlé B, de Rijk A (2012). Supporting return-to-work in the face of legislation: stakeholders' experiences with return-to-work after breast cancer in Belgium. J Occup Rehabil 22: 241-51.

Tubach F, Leclerc A, Landre MF, Pietri-Taleb F (2002) Risk factors for sick leave due to low back pain: a prospective study. J Occup Environ Med 44: 451-8.

van den Heuvel SG, Ariëns GA, Boshuizen HC, Hoogendoorn WE, Bongers PM (2004) Prognostic factors related to recurrent low-back pain and sickness absence. Scand J Work Environ Health 30: 459-67.

van Dixhoorn J, Duivenvoorden HJ (1985) Efficacy of Nijmegen Questionnaire in recognition of the hyperventilation syndrome. J Psychosom Res 29: 199-206.

Van Nieuwenhuyse A, Fatkhutdinova L, Verbeke G, Pirenne D, Johannik K, Somville PR, Mairiaux P, Moens GF, Masschelein R (2004) Risk factors for first-ever low back pain among workers in their first employment. Occup Med (Lond.) 54: 513-9.

Van Nieuwenhuyse A, Somville PR, Crombez G, Burdorf A, Verbeke G, Johannik K, Van den Bergh O, Masschelein R, Mairiaux P, Moens GF; BelCoBack Study Group (2006) The role of physical workload and pain-related fear in the development of low back pain in young workers: evidence from the BelCoBack Study; results after one year of follow-up. Occup Environ Med 63, 45-52.

van Poppel MN, de Vet HC, Koes BW, Smid T, Bouter LM (2002) Measuring sick leave: a comparison of self-reported data on sick leave and data from company records. Occup Med (Lond.) 52: 485-90.

van Tulder MW, Koes BW, Bouter LM (1995) A cost-of-illness study of back pain in The Netherlands. Pain 62: 233-40. 
Vlaeyen JW, Crombez G (1998) The modified Tampa Scale for Kinesiophobia for use in a nonpain population. Unpublished authorised Dutch/Flemish version.

Von Korff M, Ormel J, Keefe FJ, Dworkin SF (1992) Grading the severity of chronic pain. Pain 50: $133-49$.

Wasiak R, Verma S, Pransky G, Webster B (2004). Risk Risk factors for recurrent episodes of care and work disability: case of low back pain. J Occup Environ Med 46: 68-76.

Watson D, Clark LA, Tellegen A (1988) Development and validation of brief measures of positive and negative affect: the PANAS scales. J Pers Soc Psychol 54: 1063-70.

Wickstrom GJ, Pentti J (1998) Occupational factors affecting sick leave attributed to low-back pain. Scand J Work Environ Health 24: 145-52. 
Table 1a : Categorical characteristics of the study population $(n=716)$

\begin{tabular}{|c|c|c|c|}
\hline \multicolumn{2}{|l|}{ Variable } & \multirow[t]{2}{*}{$\mathbf{n}$} & $\%$ \\
\hline \multicolumn{3}{|l|}{ CURRENT PHYSICAL LOAD } & \\
\hline \multirow[t]{3}{*}{ Bent and twisted position } & No & 448 & 63.5 \\
\hline & $\leq 2$ hours/day & 181 & 25.7 \\
\hline & $>2$ hours/day & 76 & 10.8 \\
\hline \multirow[t]{3}{*}{ Driving vehicles or machines } & No & 408 & 57.8 \\
\hline & $\leq 6$ hours/day & 141 & 19.9 \\
\hline & $>6$ hours/day & 158 & 22.3 \\
\hline \multirow[t]{3}{*}{ Pushing or pulling of loads } & No & 324 & 45.7 \\
\hline & $<1$ time/hour & 201 & 28.3 \\
\hline & $\geq 1$ time/hour & 184 & 26.0 \\
\hline \multirow[t]{6}{*}{ Lifting or carrying of loads } & No & 123 & 17.5 \\
\hline & $\leq 10 \mathrm{~kg}$ & 84 & 11.9 \\
\hline & $>10 \mathrm{~kg}, \leq 25 \mathrm{~kg}, \leq 12$ times an hour & 122 & 17.4 \\
\hline & $>10 \mathrm{~kg}, \leq 25 \mathrm{~kg},>12$ times an hour & 50 & 7.1 \\
\hline & $>25 \mathrm{~kg}, \leq 12$ times an hour & 311 & 44.3 \\
\hline & $>25 \mathrm{~kg},>12$ times an hour & 13 & 1.8 \\
\hline Sitting for long periods & Yes & 138 & 19.4 \\
\hline Standing for long periods & Yes & 182 & 25.9 \\
\hline Ability to change posture regularly & No & 90 & 12.7 \\
\hline \multirow[t]{2}{*}{ Working schedule } & Night duty & 185 & 26.2 \\
\hline & Day duty & 522 & 73.8 \\
\hline Percentage of employment & More than $75 \%$ & 626 & 88.3 \\
\hline \multicolumn{4}{|l|}{ Extra-professional } \\
\hline Sporting activities at least weekly & No & 326 & 45.7 \\
\hline Embellishment works at home & Yes & 418 & 59.7 \\
\hline Construction works at home & Yes & 145 & 21.9 \\
\hline \multicolumn{4}{|l|}{ PSYCHOSOCIAL WORK LOAD } \\
\hline \multirow[t]{3}{*}{ Possibilities to develop skills } & Low $(\leq 32)$ & 197 & 28.2 \\
\hline & Moderate $(>32-\leq 36)$ & 195 & 27.9 \\
\hline & $\operatorname{High}(>36)$ & 307 & 43.9 \\
\hline \multirow[t]{3}{*}{ Decision authority } & Low $(\leq 28)$ & 137 & 19.5 \\
\hline & Moderate $(>28-\leq 36)$ & 301 & 43.0 \\
\hline & High $(>36)$ & 263 & 37.5 \\
\hline \multirow[t]{3}{*}{ Psychological job demands } & Low $(\leq 30)$ & 269 & 40.0 \\
\hline & Moderate $(>30-\leq 34)$ & 200 & 29.7 \\
\hline & High $(>34)$ & 204 & 30.3 \\
\hline \multirow[t]{3}{*}{ Supervisor support } & Low $(\leq 11)$ & 138 & 20.1 \\
\hline & Moderate $(>11-\leq 12)$ & 207 & 30.2 \\
\hline & $\operatorname{High}(>12)$ & 340 & 49.7 \\
\hline \multirow[t]{3}{*}{ Co-worker support } & Low $(\leq 12)$ & 156 & 22.9 \\
\hline & Moderate $(>12-\leq 13)$ & 76 & 11.2 \\
\hline & $\operatorname{High}(>13)$ & 448 & 65.9 \\
\hline \multirow[t]{3}{*}{ Job insecurity } & Low $(\leq 8)$ & 246 & 35.9 \\
\hline & Moderate $(>8-\leq 10)$ & 250 & 36.5 \\
\hline & High $(>10)$ & 189 & 27.6 \\
\hline \multirow[t]{3}{*}{ Job dissatisfaction } & Low $(\leq 9)$ & 301 & 44.2 \\
\hline & Moderate $(>9-\leq 11)$ & 221 & 32.5 \\
\hline & $\operatorname{High}(>11)$ & 159 & 23.3 \\
\hline
\end{tabular}


Table 1a (ct'd): Categorical characteristics of the study population (n=716)

\begin{tabular}{|c|c|c|c|}
\hline Variable & & $\mathbf{n}$ & $\%$ \\
\hline \multicolumn{4}{|l|}{ INDIVIDUAL VARIABLES } \\
\hline Gender & Women & 433 & 60.5 \\
\hline \multirow[t]{2}{*}{ Language } & Dutch-speaking & 504 & 70.4 \\
\hline & French-speaking & 212 & 29.6 \\
\hline \multirow[t]{4}{*}{ Education } & Higher university & 41 & 5.8 \\
\hline & Higher non-university & 263 & 37.0 \\
\hline & Higher secondary/professional & 281 & 39.5 \\
\hline & $\begin{array}{l}\text { No diploma - primary school- } \\
\text { lower secondary/professional }\end{array}$ & 126 & 17.7 \\
\hline \multirow[t]{3}{*}{ Smoking } & Never smoked & 430 & 61.1 \\
\hline & Ex-smoker & 88 & 12.5 \\
\hline & Current smoker & 186 & 26.4 \\
\hline \multirow[t]{4}{*}{ Body mass index BMI $\left(\mathrm{kg} / \mathrm{m}^{2}\right)$} & Normal $(\geq 20-<25)$ & 379 & 56.4 \\
\hline & Underweight $(<20)$ & 110 & 16.4 \\
\hline & Overweight $(\geq 25-<30)$ & 132 & 19.6 \\
\hline & Obese $(\geq 30)$ & 51 & 7.6 \\
\hline \multirow{2}{*}{ Perceived general health } & Very good & 339 & 47.4 \\
\hline & Moderate to fair & 376 & 52.6 \\
\hline \multicolumn{4}{|l|}{ In the 12 months before inclusion: } \\
\hline Complaints of the neck & Yes & 194 & 27.1 \\
\hline Complaints of the back & Yes & 345 & 48.2 \\
\hline Complaints of the upper limbs & Yes & 134 & 18.7 \\
\hline Complaints of the lower limbs & Yes & 180 & 25.1 \\
\hline \multirow[t]{3}{*}{ Pain-related fear } & Low $(\leq 35)$ & 240 & 33.6 \\
\hline & Moderate $(>35-\leq 41)$ & 238 & 33.4 \\
\hline & High $(>41)$ & 235 & 33.0 \\
\hline \multirow[t]{3}{*}{ Catastrophizing of pain } & Low $(\leq 10)$ & 237 & 33.2 \\
\hline & Moderate $(>10-\leq 17)$ & 249 & 35.0 \\
\hline & High $(>18)$ & 227 & 31.8 \\
\hline \multirow[t]{3}{*}{ Somatisation } & Low $(\leq 16)$ & 240 & 33.6 \\
\hline & Moderate $(>16-\leq 20)$ & 240 & 33.6 \\
\hline & High $(>20)$ & 235 & 32.8 \\
\hline \multirow{3}{*}{ Negative affectivity } & Low $(\leq 47)$ & 288 & 40.2 \\
\hline & Moderate $(>47-\leq 58)$ & 202 & 28.3 \\
\hline & High $(>58)$ & 225 & 31.5 \\
\hline
\end{tabular}


Table 1b : Continuous characteristics of the study population $(n=716)$

Variable

Mean

Median

SD*

$\mathbf{I Q R} * *$

CURRENT PHYSICAL LOAD

Seniority in the current function (years)

3.6

18674.0

3.0

15000.0

2.7

$1.0-5.0$

Motor vehicle driving outside the work $(\mathrm{km} /$ year $)$

26.2

26.0

2.7

$24-29$

*SD = Standard deviation of the mean

**IQR = Interquartile Range 
$\underline{\text { Table } 2}$

Occurrence of sick leave due to LBP after one year of follow-up

n Sick leave due to LBP at follow up

\begin{tabular}{lcccc} 
& & $\mathbf{n}$ & $\%$ & $\mathbf{9 5 \%}$ CI \\
\hline Study population & & & & \\
\hline & 716 & 42 & 5.9 & $(4.1-7.6)$ \\
Men & 283 & 21 & 7.4 & $(4.4-10.5)$ \\
Women & 433 & 21 & 4.9 & $(2.8-6.9)$ \\
\hline
\end{tabular}




\begin{tabular}{|c|c|c|c|c|c|c|c|}
\hline \multicolumn{2}{|l|}{ Variable at baseline } & \multicolumn{3}{|c|}{$\underline{\text { SLLBP }} \underline{\text { at t } 1}$} & $* \mathbf{P}$ value & $\mathbf{R R}$ & $95 \% \mathrm{CI}$ \\
\hline \multirow{2}{*}{\multicolumn{8}{|c|}{$\begin{array}{l}\text { CURRENT PHYSICAL LOAD } \\
\text { Professional }\end{array}$}} \\
\hline & & & & & & & \\
\hline \multirow[t]{3}{*}{$\overline{\text { Bent and twisted position }}$} & No & 448 & 23 & 5.1 & \multirow[t]{3}{*}{0.173} & 1.00 & \\
\hline & $\leq 2$ hours/day & 179 & 11 & 6.1 & & 1.20 & $(0.60 ; 2.40)$ \\
\hline & $>2$ hours/day & 75 & 8 & 10.7 & & 2.08 & $(0.97 ; 4.46)$ \\
\hline \multirow{3}{*}{$\begin{array}{l}\text { Driving vehicles or } \\
\text { machines at work }\end{array}$} & No & 406 & 16 & 3.9 & \multirow[t]{3}{*}{0.024} & 1.00 & \\
\hline & $\leq 6$ hours/day & 140 & 14 & 10.0 & & 2.54 & $(1.27-5.08)$ \\
\hline & $>6$ hours/day & 158 & 11 & 7.0 & & 1.77 & $(0.84-3.72)$ \\
\hline \multirow[t]{3}{*}{ Pushing or pulling of loads } & No & 324 & 15 & 4.6 & \multirow[t]{3}{*}{0.389} & 1.00 & \\
\hline & $<1$ time/hour & 200 & 15 & 7.5 & & 1.62 & $(0.81 ; 3.25)$ \\
\hline & $\geq 1$ time/hour & 182 & 11 & 6.0 & & 1.31 & $(0.61 ; 2.79)$ \\
\hline \multirow{6}{*}{ Lifting or carrying of loads } & No & 123 & 5 & 4.1 & \multirow{6}{*}{0.127} & 1.00 & \\
\hline & $\leq 10 \mathrm{~kg}$ & 84 & 7 & 8.3 & & 2.05 & $(0.67 ; 6.25)$ \\
\hline & $>10 \mathrm{~kg}, \leq 25 \mathrm{~kg}, \leq 12$ times an hour & 121 & 10 & 8.3 & & 2.03 & $(0.72 ; 5.78)$ \\
\hline & $>10 \mathrm{~kg}, \leq 25 \mathrm{~kg},>12$ times an hour & 50 & 4 & 8.0 & & 1.97 & $(0.55 ; 7.04)$ \\
\hline & $>25 \mathrm{~kg}, \leq 12$ times an hour & 310 & 13 & 4.2 & & 1.03 & $(0.38 ; 2.83)$ \\
\hline & $>25 \mathrm{~kg},>12$ times an hour & 12 & 2 & 16.7 & & 4.10 & $(0.89 ; 18.87)$ \\
\hline \multirow[t]{2}{*}{ Sitting for long periods } & No & 570 & 36 & 6.3 & \multirow[t]{2}{*}{0.224} & 1.00 & \\
\hline & Yes & 138 & 5 & 3.6 & & 0.57 & $(0.23-1.43)$ \\
\hline \multirow[t]{2}{*}{ Standing for long periods } & No & 521 & 31 & 6.0 & \multirow[t]{2}{*}{0.858} & 1.00 & \\
\hline & Yes & 179 & 10 & 5.6 & & 0.94 & $(0.47-1.88)$ \\
\hline Ability to change posture & Yes & 617 & 33 & 5.3 & \multirow[t]{2}{*}{0.076} & 1.00 & \\
\hline Regularly & No & 89 & 9 & 10.1 & & 1.89 & $(0.94-3.82)$ \\
\hline
\end{tabular}


Table 3a Categorical risk factors for the occurrence of sick leave due to low back pain after one year of follow-up (SL $\mathrm{LBP}_{\mathrm{L}}$ at $\left.\mathrm{t} 1\right)$ in univariate analyses.

(ct'd)

\begin{tabular}{|c|c|c|c|c|c|c|c|}
\hline Variable at baseline & \multicolumn{7}{|c|}{$\underline{S L}_{\mathrm{LBP}} \underline{\text { at t } 1}$} \\
\hline \multirow[t]{2}{*}{ Working schedule } & Night duty & 185 & 9 & 4.9 & 0.576 & 1.00 & \\
\hline & Day duty & 519 & 31 & 6.0 & & 1.23 & $(0.60-2.53)$ \\
\hline \multirow[t]{2}{*}{ Percentage of employment } & More than $75 \%$ & 624 & 37 & 5.9 & 1.000 & 1.00 & \\
\hline & $75 \%$ or less & 82 & 5 & 6.1 & & 0.97 & $(0.39-2.40)$ \\
\hline \multicolumn{8}{|l|}{ Extra-professional } \\
\hline \multirow{2}{*}{$\begin{array}{l}\text { Sporting activities at least } \\
\text { weekly }\end{array}$} & Yes & 386 & 20 & 5.2 & 0.371 & 1.00 & \\
\hline & No & 325 & 22 & 6.8 & & 1.31 & $(0.73-2.35)$ \\
\hline \multirow{2}{*}{$\begin{array}{l}\text { Embellishment works at } \\
\text { home }\end{array}$} & No & 281 & 12 & 4.3 & 0.171 & 1.00 & \\
\hline & Yes & 416 & 28 & 6.7 & & 1.58 & $(0.82-3.05)$ \\
\hline \multirow{2}{*}{$\begin{array}{l}\text { Construction works at } \\
\text { home }\end{array}$} & No & 514 & 31 & 6.0 & 0.583 & 1.00 & \\
\hline & Yes & 145 & 7 & 4.8 & & 0.80 & $(0.36-1.78)$ \\
\hline \multicolumn{8}{|c|}{ PSYCHOSOCIAL WORK LOAD } \\
\hline \multirow{3}{*}{$\begin{array}{l}\text { Possiblities to develop } \\
\text { skills }\end{array}$} & High & 197 & 4 & 2.0 & 0.023 & 1.00 & \\
\hline & Moderate & 193 & 12 & 6.2 & & 3.06 & $(1.01 ; 9.35)$ \\
\hline & Low & 306 & 24 & 7.8 & & 3.86 & $(1.36 ; 10.99)$ \\
\hline \multirow[t]{3}{*}{ Decision authority } & Low & 137 & 9 & 6.6 & 0.888 & 1.00 & \\
\hline & Moderate & 301 & 18 & 6.0 & & 0.91 & $(0.42 ; 1.98)$ \\
\hline & High & 260 & 14 & 5.4 & & 0.82 & $(0.36 ; 1.85)$ \\
\hline \multirow[t]{3}{*}{ Psychological job demands } & Low & 268 & 21 & 7.8 & 0.101 & 1.00 & \\
\hline & Moderate & 200 & 8 & 4.0 & & 0.51 & $(0.23 ; 1.13)$ \\
\hline & High & 202 & 8 & 4.0 & & 0.51 & $(0.23 ; 1.12)$ \\
\hline
\end{tabular}


Table 3a Categorical risk factors for the occurrence of sick leave due to low back pain after one year of follow-up (SL $\mathrm{LBP}_{\mathrm{LB}}$ at $\mathrm{t}$ ) in univariate analyses.

(ct'd)

\begin{tabular}{|c|c|c|c|c|c|c|c|}
\hline Variable at baseline & & \multicolumn{3}{|c|}{$\underline{S L_{L B P}}$ at t1 } & $* \mathbf{P}$ value & $\mathbf{R R}$ & $95 \% \mathrm{CI}$ \\
\hline \multirow{3}{*}{ Supervisor support } & Low & 137 & 4 & 2.9 & 0.227 & 1.00 & \\
\hline & Moderate & 206 & 15 & 7.3 & & 2.49 & $(0.85 ; 7.35)$ \\
\hline & High & 339 & 21 & 6.2 & & 2.12 & $(0.74 ; 6.06)$ \\
\hline \multirow[t]{3}{*}{ Coworker support } & Low & 156 & 7 & 4.5 & 0.510 & 1.00 & \\
\hline & Moderate & 75 & 3 & 4.0 & & 0.89 & $(0.24 ; 3.36)$ \\
\hline & High & 446 & 29 & 6.5 & & 1.45 & $(0.65 ; 3.24)$ \\
\hline \multirow[t]{3}{*}{ Job insecurity } & Low & 245 & 10 & 4.1 & 0.378 & 1.00 & \\
\hline & Moderate & 249 & 16 & 6.4 & & 1.57 & $(0.73 ; 3.40)$ \\
\hline & High & 188 & 13 & 6.9 & & 1.69 & $(0.76 ; 3.77)$ \\
\hline \multirow[t]{3}{*}{ Job dissatisfaction } & Low & 300 & 18 & 6.0 & 0.230 & 1.00 & \\
\hline & Moderate & 221 & 9 & 4.1 & & 0.68 & $(0.31 ; 1.48)$ \\
\hline & High & 157 & 13 & 8.3 & & 1.38 & $(0.69 ; 2.74)$ \\
\hline \multicolumn{8}{|c|}{ INDIVIDUAL VARIABLES } \\
\hline \multirow[t]{2}{*}{ Gender } & Men & 282 & 21 & 7.4 & 0.153 & 1.00 & \\
\hline & Women & 431 & 21 & 4.9 & & 0.65 & $(0.36 ; 1.18)$ \\
\hline \multirow[t]{2}{*}{ Language } & Dutch-speaking & 502 & 28 & 5.6 & 0.584 & 1.00 & \\
\hline & French-speaking & 211 & 14 & 6.6 & & 1.19 & $(0.64 ; 2.21)$ \\
\hline \multirow[t]{3}{*}{ Smoking } & Never smoked & 430 & 21 & 4.9 & 0.296 & 1.00 & \\
\hline & Ex-smoker & 88 & 7 & 8.0 & & 1.63 & $(0.71 ; 3.72)$ \\
\hline & Current smoker & 183 & 14 & 7.7 & & 1.57 & $(0.81 ; 3.01)$ \\
\hline
\end{tabular}


Table 3a Categorical risk factors for the occurrence of sick leave due to low back pain after one year of follow-up (SL $\mathrm{LBP}_{\mathrm{LB}}$ at $\left.\mathrm{t} 1\right)$ in univariate analyses.

(ct'd)

\begin{tabular}{|c|c|c|c|c|c|c|c|}
\hline \multirow[t]{2}{*}{ Variable at baseline } & \multicolumn{7}{|c|}{$\underline{S L}_{L B P} \underline{\text { at t1 }}$} \\
\hline & & $\mathbf{n}$ & $\mathbf{n}$ & $\%$ & *P value & $\mathbf{R R}$ & $95 \% \mathrm{CI}$ \\
\hline \multirow[t]{4}{*}{ Education } & Higher university & 41 & 3 & 7.3 & 0.061 & 1.00 & \\
\hline & Higher non-university & 263 & 8 & 3.0 & & 0.42 & $(0.11 ; 1.50)$ \\
\hline & Higher secondary/professional & 279 & 18 & 6.5 & & 0.88 & $(0.27 ; 2.87)$ \\
\hline & $\begin{array}{l}\text { No diploma - primary school - lower } \\
\text { secondary/professional }\end{array}$ & 125 & 12 & 9.6 & & 1.31 & $(0.39 ; 4.42)$ \\
\hline \multirow[t]{4}{*}{ Body mass index $\left(\mathrm{kg} / \mathrm{m}^{2}\right)$} & Normal $(\geq 20-<25)$ & 378 & 18 & 4.8 & 0.021 & 1.00 & \\
\hline & Underweight $(<20)$ & 109 & 3 & 2.8 & & 0.58 & $(0.17 ; 1.93)$ \\
\hline & Overweight $(\geq 25-<30)$ & 132 & 10 & 7.6 & & 1.59 & $(0.75 ; 3.36)$ \\
\hline & Obese $(\geq 30)$ & 50 & 7 & 14.0 & & 2.94 & $(1.29 ; 6.67)$ \\
\hline \multirow[t]{2}{*}{ Perceived general health } & Very good & 339 & 10 & 2.9 & 0.002 & 1.00 & \\
\hline & Moderate to fair & 373 & 31 & 8.3 & & 2.82 & $(1.40 ; 5.65)$ \\
\hline \multicolumn{8}{|c|}{ In the 12 months before inclusion: } \\
\hline \multirow{2}{*}{ Complaints of the neck } & No & 520 & 33 & 6.3 & 0.396 & 1.00 & \\
\hline & Yes & 193 & 9 & 4.7 & & 0.73 & $(0.36 ; 1.51)$ \\
\hline \multirow[t]{2}{*}{ Complaints of the back } & No & 369 & 19 & 5.1 & 0.384 & 1.00 & \\
\hline & Yes & 344 & 23 & 6.7 & & 1.30 & $(0.72 ; 2.34)$ \\
\hline \multirow{2}{*}{$\begin{array}{l}\text { Complaints of the } \\
\text { upper limbs }\end{array}$} & No & 581 & 28 & 4.8 & 0.011 & 1.00 & \\
\hline & Yes & 132 & 14 & 10.6 & & 2.20 & $(1.19 ; 4.07)$ \\
\hline Complaints of the & No & 535 & 32 & 6.0 & 0.858 & 1.00 & \\
\hline lower limbs & Yes & 178 & 10 & 5.6 & & 0.94 & $(0.47 ; 1.87)$ \\
\hline \multirow[t]{3}{*}{ Pain-related fear } & Low & 240 & 12 & 5.0 & 0.538 & 1.00 & \\
\hline & Moderate & 237 & 13 & 5.5 & & 1.10 & $(0.51 ; 2.35)$ \\
\hline & High & 233 & 17 & 7.3 & & 1.46 & $(0.71 ; 2.99)$ \\
\hline
\end{tabular}


Table 3a Categorical risk factors for the occurrence of sick leave due to low back pain after one year of follow-up (SL $\mathrm{LBP}_{\mathrm{L}}$ at $\left.\mathrm{t} 1\right)$ in univariate analyses.

(ct'd)

\begin{tabular}{|c|c|c|c|c|c|c|c|}
\hline \multirow[t]{2}{*}{ Variable at baseline } & & \multicolumn{3}{|c|}{$\underline{S L}_{L B P}$ at t1 } & \multirow[b]{2}{*}{$* \mathbf{P}$ value } & \multirow[b]{2}{*}{$\mathbf{R R}$} & \multirow[b]{2}{*}{$95 \% \mathrm{CI}$} \\
\hline & & $\mathbf{n}$ & n & $\%$ & & & \\
\hline \multirow[t]{3}{*}{ Catastrophizing of pain } & Low & 235 & 12 & 5.1 & 0.463 & 1.00 & \\
\hline & Moderate & 249 & 13 & 5.2 & & 1.02 & $(0.48 ; 2.19)$ \\
\hline & High & 226 & 17 & 7.5 & & 1.47 & $(0.72 ; 3.01)$ \\
\hline \multirow[t]{3}{*}{ Somatisation } & Low & 239 & 17 & 7.1 & 0.616 & 1.00 & \\
\hline & Moderate & 240 & 13 & 5.4 & & 0.76 & $(0.38 ; 1.53)$ \\
\hline & High & 233 & 12 & 5.2 & & 0.72 & $(0.35 ; 1.48)$ \\
\hline \multirow[t]{3}{*}{ Negative affectivity } & Low & 287 & 22 & 7.7 & 0.213 & 1.00 & \\
\hline & Moderate & 202 & 8 & 4.0 & & 0.52 & $(0.23 ; 1.14)$ \\
\hline & High & 223 & 12 & 5.4 & & 0.70 & $(0.36 ; 1.39)$ \\
\hline
\end{tabular}

$\mathrm{RR}=$ relative risk $/ 95 \% \mathrm{CI}=95 \%$ confidence interval $/ * \mathrm{P}$ value calculated with Chi-square tests or Fisher Exact tests 
Variable at baseline

$\underline{\text { SLLP at t1 }}$ Median (Q1-Q3)

\section{Professional}

Seniority in the current function (years)

ssional

Motor vehicle driving outside the work

$\quad \underline{\mathrm{SL}}_{\mathrm{LBP}} \underset{\text { Median }}{\text { at } 1}(\mathrm{Q1}-\mathrm{Q3})$

n

No SL Median (Q1-Q3) (km/year)

\section{INDIVIDUAL VARIABLES}

Age (years) 42
$3(2-6)$
657

$3 \quad(1-5) \quad 0.188$

* P value calculated with Mann Whitney U tests
$20000 \quad(12000-30000) \quad 560$

$15000(10000-25000) \quad \mathbf{0 . 0 1 8}$ 


\begin{tabular}{|c|c|c|c|c|c|c|c|c|c|c|c|c|c|}
\hline \multirow[b]{2}{*}{ Variable at baseline } & \multirow[b]{2}{*}{$\mathbf{n}$} & \multicolumn{2}{|c|}{$\underline{\text { SL }} \underline{\underline{L B P}} \underline{\text { at t } 1}$} & \multicolumn{3}{|c|}{ UNIVARIATE ANALYSES ${ }^{1}$} & \multicolumn{3}{|c|}{$\frac{\text { MULTIVARIATE }}{\underline{\text { ANALYSES }^{2}}}$} & \multicolumn{2}{|c|}{$\underline{\text { AF exposed }}$} & \multicolumn{2}{|c|}{$\underline{\text { PAF total }}$} \\
\hline & & $\mathbf{n}$ & $\%$ & P value & $\mathbf{R R}$ & $95 \% \mathrm{CI}$ & $P$ value & $\mathbf{R R}$ & $95 \% \mathrm{CI}$ & $\mathbf{A F}$ & $95 \% \mathrm{CI}$ & PAF & $95 \% \mathrm{CI}$ \\
\hline \multicolumn{14}{|c|}{ PSYCHOSOCIAL WORKLOAD } \\
\hline Possibilities to develop skills & & & & 0.005 & & & 0.008 & & & & & & \\
\hline High & 154 & 2 & 1.3 & & 1.00 & & & 1.00 & & & & & \\
\hline Moderate & 151 & 10 & 6.6 & & 5.10 & $(1.12-23.27)$ & & 5.01 & $(1.10-22.88)$ & 0.80 & $(0.10-0.96)$ & 0.22 & $(0.07-0.60)$ \\
\hline Low & 234 & 20 & 8.5 & & 6.58 & $(1.54-28.16)$ & & 6.08 & $(1.42-26.07)$ & 0.84 & $(0.30-0.96)$ & 0.31 & $(0.04-0.69)$ \\
\hline \multicolumn{14}{|l|}{ INDIVIDUAL VARIABLES } \\
\hline Body mass index & & & & 0.019 & & & 0.030 & & & & & & \\
\hline Normal & 307 & 14 & 4.6 & & 1.00 & & & 1.00 & & & & & \\
\hline Underweight & 82 & 2 & 2.4 & & 0.54 & $(0.12-2.35)$ & & 0.52 & $(0.12-2.27)$ & & & & \\
\hline Overweight & 110 & 9 & 8.2 & & 1.79 & $(0.77-4.15)$ & & 1.74 & $(0.75-4.04)$ & & & & \\
\hline Obese & 40 & 7 & 17.5 & & 3.84 & $(1.55-9.51)$ & & 3.41 & $(1.37-8.48)$ & 0.71 & $(0.27-0.88)$ & 0.30 & $(0.06-0.58)$ \\
\hline
\end{tabular}

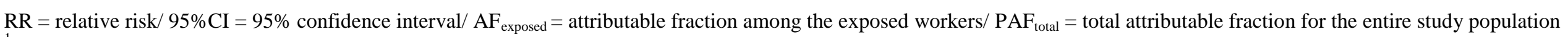
${ }^{1}$ Cox-regression

${ }^{2}$ Cox-regression, backward selection, $\mathrm{P}_{\text {in }}=0.10, \mathrm{P}_{\text {out }}=0.05$

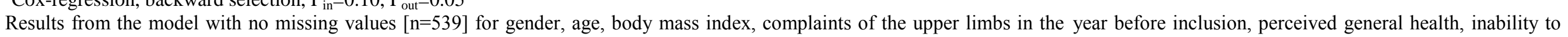
change posture regularly, motor vehicle driving outside the work, and possibilities to develop skills. 